\title{
Long Non-Coding RNAs in Cardiac Remodeling
}

\author{
Shutong Shen ${ }^{a}$ Huimin Jiang ${ }^{b, c}$ Yihua Beid,e Junjie Xiaod,e Xinli Li ${ }^{a}$ \\ aDepartment of Cardiology, The First Affiliated Hospital of Nanjing Medical University, Nanjing, \\ ${ }^{b}$ Clinical Laboratory Center, Beijing Hospital of Traditional Chinese Medicine, Beijing, 'Department of \\ Cardiology, Fuwai Hospital, National Center for Cardiovascular Diseases, Peking Union Medical College, \\ Beijing, 'Cardiac Regeneration and Ageing Lab, School of Life Science, Shanghai University, Shanghai, \\ eShanghai Key Laboratory of Bio-Energy Crops, School of Life Science, Shanghai University, Shanghai, \\ China
}

\section{Key Words}

Long non-coding RNAs • Cardiac remodeling • Hypertrophy • Apoptosis

\begin{abstract}
Cardiac remodeling occurs after stress to the heart, manifested as pathological processes, including hypertrophy and apoptosis of cardiomyocytes, dysfunction of vascular endothelial cells and vascular smooth muscle cells as well as differentiation and proliferation of fibroblasts, ultimately resulting in progression of cardiovascular diseases. Emerging evidence has revealed that long non-coding RNAs (IncRNAs) acted as powerful and dynamic modifiers of cardiac remodeling. LncRNAs including Chaer, Chast, Mhrt, CHRF, ROR, H19, and MIAT have been implicated in cardiac hypertrophy while NRF, H19, APF, CARL, UCA, Mhrt and several other IncRNAs (n379599, n379519, n384640, n380433 and n410105) in cardiomyocyte loss and extracellular matrix remodeling. In addition, MALAT1 and TGFB2-OT1 have been reported to contribute to vascular endothelial cells dysfunction while lincRNA-p21 and Inc-Ang362 to vascular smooth muscle cells proliferation. Thus, manipulation of IncRNA expression levels through either the inhibition of disease-up-regulated IncRNAs or increasing disease-downregulated IncRNAs represents novel therapeutic strategies for cardiac remodeling.

(C) 2017 The Author(s)

Published by S. Karger AG, Basel
\end{abstract}

\section{Introduction}

Cardiovascular diseases, especially coronary atherosclerotic disease and heart failure (HF), affect more than $20 \%$ of the population aged 40 and over. Though the clinical management is improving, mortality rates of $\mathrm{HF}$ remain about $50 \%$ within 5 years of diagnosis, making HF a leading cause of morbidity and mortality in industrialized countries $[1,2]$. Cardiac remodeling, which refers to changes that result in the rearrangement of normal structures of the heart and vessel [3], is a chronic maladaptive process characterized

S. Shen and $\mathrm{H}$. Jiang contributed equally to this work.

Dr. Xinli Li and Dr. Junjie Xiao

KARGER
Department of Cardiology, The First Affiliated Hospital of Nanjing Medical University, 300 Guangzhou Road, Nanjing 210029 and Cardiac Regeneration and Ageing Lab, School of Life Science, Shanghai University, 333 Nan Chen Road, Shanghai 200444 (China)

E-Mail xinli3267_nj@hotmail.com/junjiexiao@shu.edu.cn 
by progressive myocardial hypertrophy, apoptosis, ventricular dilatation, fibrosis, vascular dysfunction, finally resulting in HF $[4,5]$. Preventing or reversing cardiac remodeling is a key strategy for the treatment of HF [6] and further efforts are highly needed to explore the mechanisms underlying cardiac remodeling.

Non-coding RNAs (ncRNAs) cover more than 98\% of the human genome [7]. Among which, small ncRNAs, such as microRNAs (miRNAs, miRs), have been intensely investigated for many years while studies on long ncRNAs (lncRNAs) just started in recent years. LncRNAs are defined as transcripts that are longer than 200 nucleotides and do not code for proteins in most cases, but basepair with DNA or RNA in a sequence-specific manner, thus regulating gene expression. LncRNAs can be classified into 4 main categories based on the generegulating mechanism: i) signal lncRNA, which can regulate gene expression in a time and space manner; ii) decoy lncRNA, which can titrate transcription factors and other proteins away from chromatin, or titrate miRNAs out from their target; iii) guide IncRNA, which can recruit chromatin modifying enzymes to target genes, either in cis (near the site of lncRNA production) or in trans to distant target genes; and iv) scaffold IncRNA, which can facilitate the assembling of multiple proteins to form ribonucleoprotein (RNP) complexes, which may act on chromatin, affecting histone modifications [7-12].

Emerging data have shown that IncRNAs play a role in both the development and pathology of cardiovascular system, providing novel insights and therapeutic targets for cardiovascular diseases. Here we reviewed the progress of lncRNAs' roles in cardiac remodeling and $\mathrm{HF}$, especially the interaction between lncRNAs and other RNAs, mainly miRNAs and mRNAs (Table 1 and Fig. 1).

\section{LncRNAs in cardiac hypertrophy}

Cardiac hypertrophy is an initially adaptive response to stress or volume overload stimuli, reducing the increased wall tension and helping to maintain cardiac output [3]. The adaptive process is beneficial and can improve muscular economy at the very start, however, persistent exposure of the heart to increased load would lead to the impairment of cardiac microcirculation, resulting in tissue hypoxia and a subsequent loss of cardiomyocytes [13, 14], ultimately resulting in HF. With the advent of high-throughput RNA sequencing, a number of studies have been carried out to investigate the role of IncRNAs in cardiac hypertrophy.

\section{Chaer}

Two high-throughput RNA sequencing studies revealed approximately 15 differentially regulated lncRNAs in mouse cardiac hypertrophy model $[15,16]$. Among them, Chaer (Cardiac Hypertrophy-Associated Epigenetic Regulator) can directly interact with the catalytic subunit of polycomb repressor complex 2 (PRC2), thereby inhibiting histone H3 lysine 27 methylation at the promoter regions of genes involved in cardiac hypertrophy and thus contributing to the development of cardiac hypertrophy [17]. Along with other PRC2-interacting IncRNAs, such as Fendrrand and Bvht, which have been shown to be important in epigenetic programming during heart development, Chaer is also an epigenetic regulatory lncRNAs. Since Chaer-PRC2 interaction is only transiently enhanced at the onset of hypertrophy, while the downstream effect of this interaction seems to be long lasting in mouse transverse aortic constriction (TAC) model, inactivation of Chaer in the stressed heart may serve as a novel therapy for pathological remodeling in hypertrophic cardiomyopathy.

Mhrt

LncRNA Mhrt (Myosin Heavy Chain Associated RNA Transcripts) is the first example of IncRNA serving as chromatin remodelers and it can inhibit cardiac hypertrophy in pathological remodeling. Mhrt directly interacts with a histone acetylation factor named Brg1 and antagonizes the function of Brg1, which is activated as a chromatin-remodeling factor 


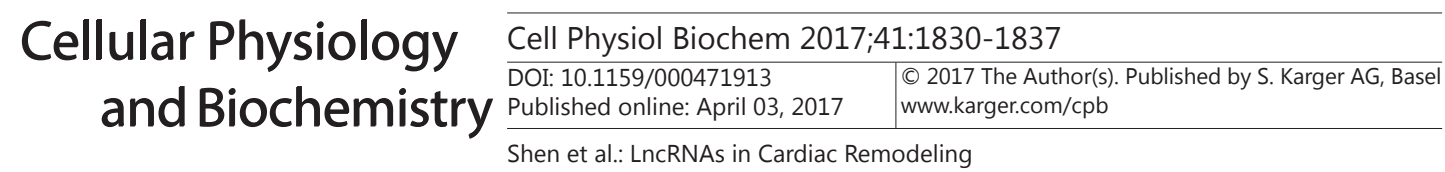

Table 1. An overview of IncRNAs in cardiac remodeling

\begin{tabular}{|c|c|c|c|c|}
\hline LncRNAs & Models & Pathological processes & Targets & Reference \\
\hline Chaer & TAC mouse & $\begin{array}{l}\text { Cardiomyocyte } \\
\text { hypertrophy }\end{array}$ & PRC2 & 17 \\
\hline Mhrt & TAC mouse & $\begin{array}{l}\text { Cardiomyocyte } \\
\text { hypertrophy }\end{array}$ & Brg1 & 18 \\
\hline Chast & TAC mouse & $\begin{array}{l}\text { Cardiomyocyte } \\
\text { hypertrophy }\end{array}$ & $\begin{array}{l}\text { Pleckstrin homology domain-containing } \\
\text { protein family } \\
\text { member } 1\end{array}$ & 20 \\
\hline CHRF & AngII-treated mouse & $\begin{array}{l}\text { Cardiomyocyte } \\
\text { hypertrophy and } \\
\text { apoptosis }\end{array}$ & $\operatorname{miR}-489$ & 21 \\
\hline ROR & $\begin{array}{l}\text { Phenylephrine-treated } \\
\text { cardiomyocytes }\end{array}$ & $\begin{array}{l}\text { Cardiomyocyte } \\
\text { hypertrophy }\end{array}$ & miR-133 & 22 \\
\hline H19 & $\begin{array}{l}\text { Phenylephrine-treated } \\
\text { cardiomyocytes }\end{array}$ & $\begin{array}{l}\text { Cardiomyocyte } \\
\text { hypertrophy }\end{array}$ & miR-675 & 23 \\
\hline MIAT & $\begin{array}{l}\text { AngII-treated mouse and } \\
\text { cardiomyocytes }\end{array}$ & $\begin{array}{l}\text { Cardiomyocyte } \\
\text { hypertrophy }\end{array}$ & miR-150 & 24 \\
\hline NRF & $\begin{array}{l}\mathrm{H}_{2} \mathrm{O}_{2} \text {-treated cardiomyocytes and } \\
\text { ischaemia/reperfusion mouse }\end{array}$ & Cardiomyocyte necrosis & miR-873 & 28 \\
\hline H19 & $\mathrm{H}_{2} \mathrm{O}_{2}$-treated cardiomyocytes & Cardiomyocyte necrosis & miR-103/107 & 29 \\
\hline APF & $\begin{array}{l}\text { Anoxia/reoxygenation } \\
\text { cardiomyocytes and } \\
\text { ischaemia/reperfusion mouse }\end{array}$ & $\begin{array}{l}\text { Cardiomyocyte } \\
\text { autophagy }\end{array}$ & miR-188-3p & 30 \\
\hline CARL & Anoxia-treated cardiomyocytes & $\begin{array}{l}\text { Mitochondrial fission } \\
\text { and cardiomyocyte } \\
\text { apoptosis }\end{array}$ & miR-539 & 31 \\
\hline UCA1 & H202-treated cardiomyocytes & $\begin{array}{l}\text { Cardiomyocyte } \\
\text { apoptosis }\end{array}$ & p27 & 32 \\
\hline Mhrt & $\begin{array}{l}\text { Doxorubicin-treated } \\
\text { cardiomyocyte }\end{array}$ & $\begin{array}{l}\text { Cardiomyocyte } \\
\text { apoptosis }\end{array}$ & Nrf2 & 33 \\
\hline $\begin{array}{l}\text { n379599, n379519, n384640, } \\
\text { n380433,n410105 }\end{array}$ & Cardiac fibroblasts & $\begin{array}{l}\text { Myofibroblast } \\
\text { differentiation }\end{array}$ & not mentioned & 34 \\
\hline MALAT1 & Hypoxia-treated HUVECs & ECs proliferation & not mentioned & 35 \\
\hline TGFB2-OT1 & $\begin{array}{l}\text { LPS-treated \&oxLDL-treated } \\
\text { HUVECs }\end{array}$ & $\begin{array}{l}\text { ECs autophagy and } \\
\text { inflammation }\end{array}$ & miR-3960, miR-4459, miR-4488 & 36 \\
\hline LincRNA-p21 & VSMCs & $\begin{array}{l}\text { VSMCs apoptosis and } \\
\text { proliferation }\end{array}$ & p53 & 37 \\
\hline LncAng362 & AngII-treated VSMC & VSMCs proliferation & miR-221 and miR-222 & 38 \\
\hline
\end{tabular}

TAC, Transverse aortic constriction; AngII, Angiotensin-2; ECs, Endothelial cells; VSMCs, Vascular smooth muscle cells; HUVECs, Human Umbilical Vein Endothelial Cells

by stress to trigger aberrant gene expression and cardiomyopathies $[18,19]$. The reciprocal Mhrt-Brg1 inhibition constitutes a negative feedback circuit in maintaining cardiac function. It is worth mentioning that Mhrt directly interacts with the helicase core of Brg1, implying Mhrt-helicase interaction may be a new mechanism by which lncRNA controls chromatin structure.

Chast

Chast (Cardiac Hypertrophy-Associated Transcript) is another pro-hypertrophic IncRNA which shows a cis-regulatory action on the gene located on the opposite strand, named Plekhm1. Chast was found to be specifically up-regulated in hearts from both mouse TAC model and aortic stenosis patients. Further studies mechanistically revealed that Chast negatively regulated Plekhm1, thus impeding cardiomyocyte autophagy and driving hypertrophy, while Chast expression was induced partly by the pro-hypertrophic transcription factor NFAT [20]. Further studies also showed that Chast had a strong effect on pathways associated with cardiac muscle morphogenesis, cardiomyopathies, and Wnt signaling by bioinformatic analysis while activation of Wnt signaling has been described as a cause of cardiac hypertrophy.

CHRF

Unlike the gene- or chromatin- regulation effect of other lncRNAs, CHRF (Cardiac Hypertrophy-Related Factor) was found to function as a sponge of miRNA. CHRF was found to be up-regulated in both hypertrophic mouse heart and human HF samples as well. In vitro studies mechanically indicated that CHRF played an anti-hypertrophic role by downregulating miR-489 expression level while miR-489 had a pro-hypertrophic effect by increasing its target gene Myd88, which could down-regulate the NF- $\kappa B$ (nuclear factor kappa-light-chain-enhancer of activated B cells) pathway [21]. 
Fig. 1. LncRNAs in cardiac remodeling.

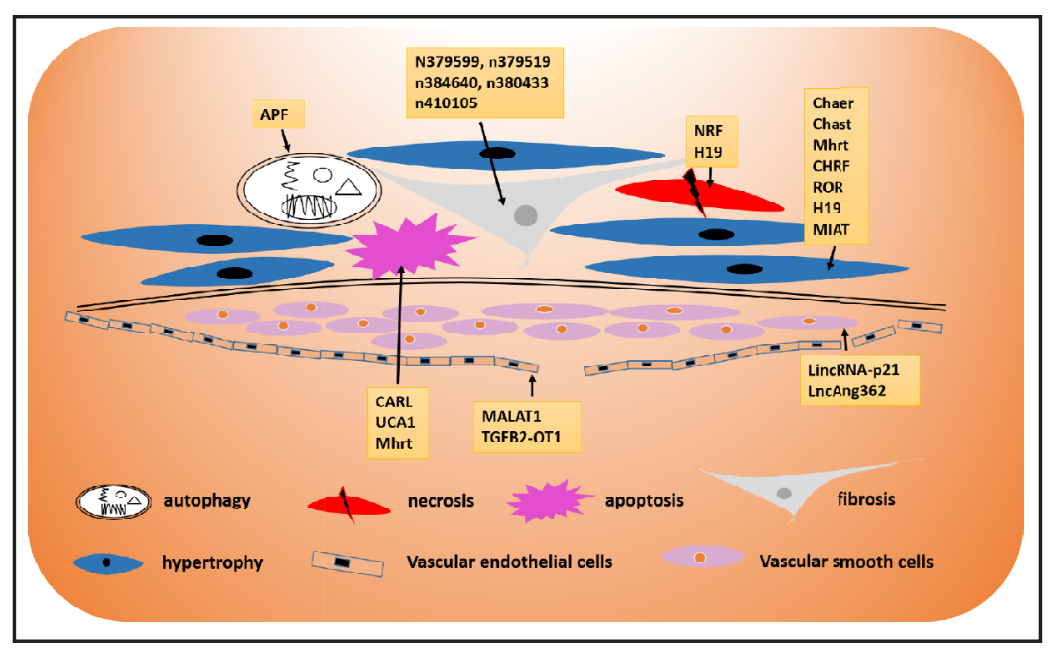

ROR

LncRNA ROR has been reported to contribute to cardiac hypertrophic responses by acting as a sponge of miR-133, whose expression was increased while ROR was knocked down. In line with this, over-expression of miR-133 also prevented the elevation of ROR. The ROR/miR-133 negative feedback circle protected cardiomyocytes from phenylephrineinduced cardiomyocytes hypertrophy [22].

\section{H19}

LncRNA H19 was firstly verified to be up-regulated in pathological cardiac hypertrophy and HF by the RNA-sequencing approach [15]. A gain-of-function and loss-of-function study performed in vitro further indicated that $\mathrm{H} 19$ protected cardiomyocytes from phenylephrineinduced hypertrophy through miR-675. Furthermore, CaMKIId, a direct target of miR-675, partially mediated the effect of H19 on cardiomyocyte hypertrophy [23].

\section{MIAT}

In an AngII-induced cardiac hypertrophy mouse model, lncRNA MIAT (Myocardial Infarction-Associated Transcript) was significantly increased and was necessary for cardiac hypertrophy. MIAT over-expression in H9C2 cells significantly reduced the miR-150 expression and MIAT acted as a sponge of miR-150 during the development of hypertrophy [24].

\section{LncRNAs in post-ischemic remodelling, mainly cardiomyocytes loss and extracellular matrix remodeling}

In addition to cardiac hypertrophy, post-ischemic remodeling, mainly manifested as the loss of cardiomyocytes and extracellular matrix remodeling, is also a common kind of cardiac remodeling. Ischemia injury releases reactive oxygen species and causes inflammation in the heart, leading to dysfunction of the energy metabolism of cardiomyocytes and finally resulting in autophagy, apoptosis or necrosis of the cardiomyocytes [25-27]. Loss of cardiomyocytes further contributes to systolic dysfunction and extracellular matrix remodeling. Several lncRNAs have been reported to participate in this process.

\section{NRF and H19 in myocardial necrosis}

LncRNA NRF (Necrosis-Related Factor) was able to induce cardiomyocyte necrosis and exacerbate ischemia/reperfusion injury in $\mathrm{H}_{2} \mathrm{O}_{2}$-treated cardiomyocytes and myocardial infarction mice by sponging miR-873 and its target gene RIPK1 (Receptor-Interacting serine/threonine-Protein Kinase 1)/RIPK3 (Receptor-Interacting serine/threonine-Pro- 
tein Kinase 3) [28]. Besides NRF, $\mathrm{H} 19$ also inhibited $\mathrm{H}_{2} \mathrm{O}_{2}$-induced cardiomyocyte necrosis in vitro by serving as a sponge for miR-103/107 and it can further regulate FADD, a target gene of miR-103/107 [29].

\section{APF in myocardial autophagy}

LncRNA APF (Autophagy Promoting Factor) acted as an enhancer of the miR-1883p/ATG7 axis both in vitro and in vivo, regulating autophagy. APF knockdown by APF siRNA exhibited a significant reduction in myocardial infarction sizes and the amelioration of myocardial function in the ischemia/reperfusion mouse hearts by targeting miR-188-3p and ATG7 [30].

CARL, UCA and Mhrt in myocardial apoptosis

LncRNA CARL (Cardiac Apoptosis-Related LncRNA) inhibited anoxia-induced mitochondrial fission and apoptosis in cardiomyocytes by impairing miR-539-dependent downregulation of PHB2 [31]. Besides that, IncRNA UCA1 (Urothelial Carcinoma-Associated 1) contributed to cardiomyocyte apoptosis by suppressing p27 expressionin in vitro [32]. Moreover, the Mhrt/Nrf2 pathway was also reported to participate in the regulation of doxorubicin-induced cardiomyocyte apoptosis [33].

LncRNAs (n379599, n379519, n384640, $n 380433$ and $n 410105)$ regulate ECM remodeling

A deep sequencing and genome-wide transcriptome analysis of RNAs from cardiac samples of 15 patients with ischemic cardiomyopathy (ICM) and 15 controls identified 35 lncRNAs that displayed a strong positive correlation with extracellular matrix (ECM) protein-coding genes and further gain- and loss-of-function studies in cardiac fibroblasts identified that 5 of the 35 lncRNAs (n379599, n379519, n384640, n380433 and $\mathrm{n} 410105)$ participated in the TGF- $\beta$ pathway to modulate the expression of ECM genes and myofibroblast differentiation [34].

\section{LncRNAs in dysfunction of vascular endothelial cells and smooth muscle cells}

Vascular remodeling, mainly characterized by vascular endothelial cells (VECs) dysfunction and vascular smooth muscle cells (VSMCs) proliferation, is closely linked to numerous pathological processes such as arteriosclerosis, thrombus formation and plaque erosion, leading to acute myocardial infarction or chronic ischemic heart disease. LncRNAs have also been reported to participate in the regulation of vascular remodeling.

MALAT1 and TGFB2-OT1 in VECs dysfunction

LncRNA MALAT1 (Metastasis-Associated Lung Adenocarcinoma Transcript 1) has been found to be highly expressed in VECs and the expression of MALAT1 was significantly increased the proliferating VECs in hypoxic conditions. Additionally, MALAT1 improved blood flow in recovery and capillary density after hindlimb ischemia, implying the angiogenesis effect of MALAT1 in the ischemic heart [35].

LncRNA TGFB2-OT1 (TGFB2 Overlapping Transcript 1) was also shown to be involved in VEC dysfunction. TGFB2-0T1 in HUVECs could regulate the levels of miR-3960, miR-4459 and miR-4488 and then regulate the expression of the miRNA targets CERS1, NAT8L and LARP1, of which NAT8L and CERS1 may participate in autophagy by regulating mitochondrial function. Moreover, over-expression of TGFB2-OT1 could induce IL-6 and IL-8 production in VECs, which indicates that TGFB2-OT1 can trigger the inflammation linkage reaction [36].

LincRNA-p21 and Lnc-Ang362 in VSMCs proliferation

LincRNA-p21 has been reported to be dramatically down-regulated in an animal model of atherosclerosis, and it could repress VSMC cell proliferation and induce apoptosis in vitro 
using loss- and gain-of-function approaches. Furthermore, lincRNA-p21 was proven to be a promising transcriptional target of p53, which could feed back to enhance p53 transcriptional activity. Finally, lincRNA-p21 expression was significantly decreased in coronary artery tissues of coronary artery disease patients. These data elucidated an important role and a proper mechanism of lincRNA-p21 in angiogenesis [37]. Besides that, another study found that lnc-Ang362 was responsible for AngII-induced VSMC proliferation by targeting miR-221 and miR-222, implying that lnc-Ang362 is a therapeutic target of AngII-associated cardiovascular disease [38].

\section{LncRNAs in genetic cardiomyopathy}

Hypertrophic cardiomyopathy (HCM) represents a most common genetic cardiomyopathy and is also a leading cause of cardiac sudden death in young people [39]. Although a total of 1400 mutations in more than 10 genes have been identified as genetic variants responsible for HCM pathology, the predominant mechanisms underlying the pathogenesis of HCM is still unknown. Since lncRNAs are involved in a variety of pathologically processes of HCM, such as varying degrees of myocardial hypertrophy, cardiomyocyte disarrangement as well as interstitial fibrosis [40, 41]. The lncRNA expression profile of HCM patients has been screened by microarray and related pathologic pathways were further analyzed by Gene ontology (GO) enrichment and KEGG analysis. They found that lncRNAs were involved in the pathogenesis of HCM, mainly through pathways underlying ribosome and oxidative phosphorylation [42]. Furthermore, another study identified 2 specific mitochondrial lncRNAs named uc004cov.4 and uc022bqu.1 as potential useful clinical biomarkers for hypertrophic obstructive cardiomyopathy (HOCM) [43].

\section{Conclusions}

LncRNAs could regulate multiple pathological processes of cardiac remodeling, including myocardial hypertrophy, autophagy, necrosis, apoptosis, fibrosis as well as vascular cell apoptosis and proliferation. Therefore, to manipulate lncRNA expression levels through either the inhibition of disease-up-regulated lncRNAs or increasing disease-down-regulated lncRNAs represents novel therapeutic strategies for cardiac remodeling. To date, various studies have been successfully performed in modulating lncRNAs in animal models by loss- and gain-of-function approaches; however, due to the innate immunity response and unpredictable toxicity of lncRNAs, no clinical trial has been performed. Nevertheless, anti-miR-122 has come to a phase II clinical trial in the treatment of hepatitis $C$ virus infection $[44,45]$, indicating the possibility of IncRNAs. In the future, with the development of sequencing and interfering technology, more IncRNAs associated with cardiac remodeling will be revealed, and more meaningful translational studies are highly needed.

\section{Acknowledgments}

This work was supported by the grants from National Natural Science Foundation of China (81570362 and 91639101 to JJ Xiao, 81670347, 81370332 and 81170201 to XL Li, 81400647 to Y Bei), the development fund for Shanghai talents (to JJ Xiao), the Basic and Clinical Grant from Peking Union Medical College (to 17JL52, HM Jiang), the Priority Academic Program Development of Jiangsu Higher Education Institutions (PAPD20102013 to XL Li). Dr. XL Li is an Associate Fellow at the Collaborative Innovation Center For Cardiovascular Disease Translational Medicine.

\section{Disclosure Statement}

The authors declare there are no conflicts of interest. 


\section{Cellular Physiology Cell Physiol Biochem 2017;41:1830-1837 \begin{tabular}{ll|l} 
and Biochemistry Published online: April03, 2017 & $\begin{array}{l}\text { (c) } 2017 \text { The Author(s). Published by S. Karger AG, Basel } \\
\text { www.karger.com/cpb }\end{array}$
\end{tabular}}

Shen et al.: LncRNAs in Cardiac Remodeling

\section{References}

1 Liu L, Wu J, Kennedy DJ: Regulation of cardiac remodeling by cardiac na+/K+-ATPase isoforms. Front Physiol 2016;7:382.

2 Yancy CW, Jessup M, Bozkurt B, Butler J, Casey DJ, Drazner MH, Fonarow GC, Geraci SA, Horwich T, Januzzi JL, Johnson MR, Kasper EK, Levy WC, Masoudi FA, McBride PE, McMurray JJ, Mitchell JE, Peterson PN, Riegel B, Sam F, Stevenson LW, Tang WH, Tsai EJ, Wilkoff BL: 2013 ACCF/AHA guideline for the management of heart failure: Executive summary: A report of the American College of Cardiology Foundation/American Heart Association Task Force on practice guidelines. Circulation 2013;128:1810-1852. Swynghedauw B: Molecular mechanisms of myocardial remodeling. Physiol Rev 1999;79:215-262. Pfeffer MA, Braunwald E: Ventricular remodeling after myocardial infarction. Experimental observations and clinical implications. Circulation 1990;81:1161-1172.

-5 Rizzello V, Poldermans D, Biagini E, Schinkel AF, Boersma E, Boccanelli A, Marwick T, Roelandt JR, Bax JJ: Prognosis of patients with ischaemic cardiomyopathy after coronary revascularisation: Relation to viability and improvement in left ventricular ejection fraction. Heart 2009;95:1273-1277.

6 Konstam MA, Kramer DG, Patel AR, Maron MS, Udelson JE: Left ventricular remodeling in heart failure: Current concepts in clinical significance and assessment. JACC Cardiovasc Imaging 2011;4:98-108.

7 Lorenzen JM, Thum T: Long noncoding RNAs in kidney and cardiovascular diseases. Nat Rev Nephrol 2016;12:360-373. Wapinski O, Chang HY: Long noncoding RNAs and human disease. Trends Cell Biol 2011;21:354-361. Moran VA, Perera RJ, Khalil AM: Emerging functional and mechanistic paradigms of mammalian long noncoding RNAs. Nucleic Acids Res 2012;40: 6391-6400.

10 Li N, Ponnusamy M, Li MP, Wang K, Li PF: The role of MicroRNA and LncRNA-MicroRNA interactions in regulating ischemic heart disease. J Cardiovascu Pharmcol Ther 2016;DOI:10.1177/1074248416667600.

11 Wang H, Bei Y, Shi J, Xiao J, Kong X: Non-Coding RNAs in cardiac aging. Cell Physiol Biochem 2015;36:16791687.

12 Gu M, Zheng A, Tu W, Zhao J, Li L, Li M, Han S, Hu X, Zhu J, Pan Y, Xu J, Yu Z: Circulating lncRNAs as novel, non-invasive biomarkers for prenatal detection of fetal congenital heart defects. Cell Physiol Biochem 2016;38:1459-1471.

- 13 Osterholt M, Nguyen TD, Schwarzer M, Doenst T: Alterations in mitochondrial function in cardiac hypertrophy and heart failure. Heart Fail Rev 2013;18:645-656.

14 De Boer RA, Pinto YM, Van Veldhuisen DJ: The imbalance between oxygen demand and supply as a potential mechanism in the pathophysiology of heart failure: The role of microvascular growth and abnormalities. Microcirculation 2003;10:113-126.

15 Lee JH, Gao C, Peng G, Greer C, Ren S, Wang Y, Xiao X: Analysis of transcriptome complexity through RNA sequencing in normal and failing murine hearts. Circ Res 2011;109:1332-1341.

- 16 Matkovich SJ, Edwards JR, Grossenheider TC, de Guzman Strong C, Dorn GW: Epigenetic coordination of embryonic heart transcription by dynamically regulated long noncoding RNAs. Proc Natl AcadSci U S A 2014;111:12264-12269.

17 Wang Z, Zhang XJ, Ji YX, Zhang P, Deng KQ, Gong J, Ren S, Wang X, Chen I, Wang H, Gao C, Yokota T, Ang YS, Li S, Cass A, Vondriska TM, Li G, Deb A, Srivastava D, Yang HT, Xiao X, Li H, Wang Y: The long noncoding RNA Chaer defines an epigenetic checkpoint in cardiac hypertrophy. Nat Med 2016;22:1131-1139.

18 Hang CT, Yang J, Han P, Cheng H, Shang C, Ashley E, Zhou B, Chang C: Chromatin regulation by Brg1 underlies heart muscle development and disease. Nature 2010;466:62-67.

19 Han P, Li W, Lin C, Yang J, Shang C, Nurnberg ST, Jin KK, Xu W, Lin C, Lin C, Xiong Y, Chien H, Zhou B, Ashley E, Bernstein D, Chen P, Chen HV, Quertermous T, Chang C: A long noncoding RNA protects the heart from pathological hypertrophy. Nature 2014;514:102-106.

20 Viereck J, Kumarswamy R, Foinquinos A, Xiao K, Avramopoulos P, Kunz M, Dittrich M, Maetzig T, Zimmer K, Remke J, Just A, Fendrich J, Scherf K, Bolesani E, Schambach A, Weidemann F, Zweigerdt R, de Windt LJ, Engelhardt S, Dandekar T, Batkai S, Thum T: Long noncoding RNA Chast promotes cardiac remodeling. Sci Transl Med 2016;8:322r-326r.

21 Wang K, Liu F, Zhou LY, Long B, Yuan SM, Wang Y, Liu CY, Sun T, Zhang XJ, Li PF: The long noncoding RNA CHRF regulates cardiac hypertrophy by targeting miR-489. Circ Res 2014;114:1377-1388.

22 Jiang F, Zhou X, Huang J: Long Non-Coding RNA-ROR mediates the reprogramming in cardiac hypertrophy. Plos One 2016;11:e152767. 


\section{Cellular Physiology Cell Physiol Biochem 2017;41:1830-1837

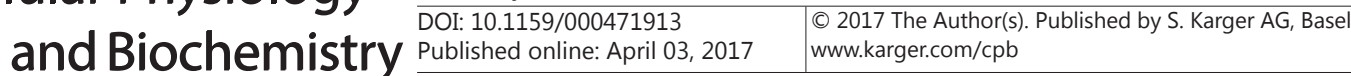

23 Liu L, An X, Li Z, Song Y, Li L, Zuo S, Liu N, Yang G, Wang H, Cheng X, Zhang Y, Yang X, Wang J: The H19 long noncoding RNA is a novel negative regulator of cardiomyocyte hypertrophy. Cardiovasc Res 2016;111:5665.

24 Zhu XH, Yuan YX, Rao SL, Wang P: LncRNA MIAT enhances cardiac hypertrophy partly through sponging miR-150. Eur Rev Med Pharmacol Sci 2016;20:3653-3660.

25 Braunwald E: Heart failure. JACC Heart Fail 2013;1:1-20.

26 Shirakabe A, Ikeda Y, Sciarretta S, Zablocki DK, Sadoshima J: Aging and autophagy in the heart. Circ Res 2016;118:1563-1576.

27 Linkermann A, Hackl MJ, Kunzendorf U, Walczak H, Krautwald S, Jevnikar AM: Necroptosis in immunity and ischemia-reperfusion injury. Am J Transplant 2013;13:2797-2804.

28 Wang K, Liu F, Liu CY, An T, Zhang J, Zhou LY, Wang M, Dong YH, Li N, Gao JN, Zhao YF, Li PF: The long noncoding RNA NRF regulates programmed necrosis and myocardial injury during ischemia and reperfusion by targeting miR-873. Cell Death Differ 2016;23:1394-1405.

29 Wang J, Zhang X, Li Q Wang K, Wang Y, Jiao J, Feng C, Teng S, Zhou L, Gong Y, Zhou Z, Liu J, Wang J, Li P: MicroRNA-103/107 regulate programmed necrosis and myocardial Ischemia/Reperfusion injury through targeting FADD Novelty and significance. Circ Res 2015;117:352-363.

- 30 Wang K, Liu C, Zhou L, Wang J, Wang M, Zhao B, Zhao W, Xu S, Fan L, Zhang X, Feng C, Wang C, Zhao Y, Li $\mathrm{P}$ : APF lncRNA regulates autophagy and myocardial infarction by targeting miR-188-3p. Nat Commun 2015;6:6779.

-31 Wang K, Long B, Zhou L, Liu F, Zhou Q Liu C, Fan Y, Li P: CARL lncRNA inhibits anoxia-induced mitochondrial fission and apoptosis in cardiomyocytes by impairing miR-539-dependent PHB2 downregulation. Nat Commun 2014;5:3596.

-32 Liu Y, Zhou D, Li G, Ming X, Tu YF, Tian J, Lu H, Yu B: Long non coding RNA-UCA1 contributes to cardiomyocyte apoptosis by suppression of p27 expression. Cell Physiol Biochem 2015;35:1986-1998.

-33 Li H, Wu Y, Yin C, Chen L, Zhang Q Hu L: Obestatin attenuated doxorubicin-induced cardiomyopathy via enhancing long noncoding Mhrt RNA expression. Biomed Pharmacother 2016;81:474-481.

-34 Huang ZP, Ding Y, Chen J, Wu G, Kataoka M, Hu Y, Yang JH, Liu J, Drakos SG, Selzman CH, Kyselovic J, Qu LH, Dos RC, Pu WT, Wang DZ: Long non-coding RNAs link extracellular matrix gene expression to ischemic cardiomyopathy. Cardiovasc Res DOI:10.1093/cvr/cvw201.

-35 Michalik KM, You X, Manavski Y, Doddaballapur A, Zornig M, Braun T, John D, Ponomareva Y, Chen W, Uchida S, Boon RA, Dimmeler S: Long noncoding RNA MALAT1 regulates endothelial cell function and vessel growth. Circ Res 2014;114:1389-1397.

-36 Huang S, Lu W, Ge D, Meng N, Li Y, Su L, Zhang S, Zhang Y, Zhao B, Miao J: A new microRNA signal pathway regulated by long noncoding RNA TGFB2-OT1 in autophagy and inflammation of vascular endothelial cells. Autophagy 2015;11:2172-2183.

37 Wu G, Cai J, Han Y, Chen J, Huang ZP, Chen C, Cai Y, Huang H, Yang Y, Liu Y, Xu Z, He D, Zhang X, Hu X, Pinello L, Zhong D, He F, Yuan GC, Wang DZ, Zeng C: LincRNA-p21 regulates neointima formation, vascular smooth muscle cell proliferation, apoptosis, and atherosclerosis by enhancing p53 activity. Circulation 2014;130:1452-1465.

38 Leung A, Trac C, Jin W, Lanting L, Akbany A, Saetrom P, Schones DE, Natarajan R: Novel long noncoding RNAs are regulated by angiotensin II in vascular smooth muscle cells. Circ Res 2013;113:266-278.

39 Ho CY: Hypertrophic cardiomyopathy in 2012. Circulation 2012;125:1432-1438.

40 Maron BJ, Maron MS: Hypertrophic cardiomyopathy. Lancet 2013;381:242-255.

41 Maron BJ: Hypertrophic cardiomyopathy: A systematic review. JAMA 2002;287:1308-1320.

42 Yang W, Li Y, He F, Wu H: Microarray profiling of long non-coding RNA (lncRNA) associated with hypertrophic cardiomyopathy. BMC Cardiovasc Disord 2015;15:62.

-43 Kitow J, Derda AA, Beermann J, Kumarswarmy R, Pfanne A, Fendrich J, Lorenzen JM, Xiao K, Bavendiek U, Bauersachs J, Thum T: Mitochondrial long noncoding RNAs as blood based biomarkers for cardiac remodeling in patients with hypertrophic cardiomyopathy. Am J Physiol Heart Circ Physiol 2016;311:H707-H712.

44 Thum T, Condorelli G: Long noncoding RNAs and MicroRNAs in cardiovascular pathophysiology. Circ Res 2015;116:751-762.

45 Schonrock N, Harvey RP, Mattick JS: Long noncoding RNAs in cardiac development and pathophysiology. Circ Res 2012;111:1349-1362. 